\title{
POSSIBLE OCCUPATIONAL LUNG CANCER IN NEPAL
}

\author{
Joshi S K*, Moen B E*, Bratveit M*
}

\section{ABSTRACT}

The objective of this study was to describe the relationship between occupational exposures and the development of lung cancer among the patients attending Bhaktapur Cancer Care Center, Bhaktapur, Nepal. The study subjects consisted of 85 cases of lung cancer and a reference group of 40 cases of colon cancer. Demographic data and information about work history was obtained by a structured interview. Based on the occupational history, subjects were divided into exposed and non-exposed groups concerning carcinogenic agents. Exposure prone occupations like agriculture, construction of buildings, construction of roads and bridges, manufacturing, and transport were categorised as exposed occupations. Similarly, occupations like administrative services, business, student and housewives were categorised as non-exposed. Odd ratio (OR) and $95 \%$ confidence intervals (CI) were calculated using logistic regression. Adjustments for smoking habit, life long cigarette consumption (smoking pack year), alcohol habit, education level and age were done. The crude OR for the exposed workers was 5.59 (95\% CI: 2.47,12.6). After adjustment for smoking habit alone or for smoking habit, smoking pack year, alcohol habit, education level and age, the OR was 4.8 (95\% CI: 2.02,11.4) and 4.2 (95\% CI: 1.4,12.0), respectively.

The study shows that for the exposed workers there was an increased risk of lung cancer. The risk was significantly increased also after adjusting for smoking habit, smoking pack year, alcohol habit, age and education level.

\section{Key Words: Lung Cancer, occupation, exposure, Nepal.}

\section{INTRODUCTION}

Cancer is a worldwide public health problem and it accounts for an increasing proportion of all deaths. Malignant diseases are the second most frequent cause of death in developed countries ( $21 \%$ of all deaths) after cardiovascular diseases. In developing countries, it accounts for $7 \%$ of all deaths. Of the 7.6 million of new cases of cancer occurring each year in the world, 4 million occur in the developing countries. The overall incidence is slightly higher in males than in females. ${ }^{1}$ The most frequent cancer type among males in the developing countries is in the lungs, accounting for about 430,000 new cases in 2000 followed by stomach cancer (350,000 new cases in 2000). Lung cancer was the most frequent cancer in the world for males in 2000, with a total estimated number of about 900,000 new cases per year, $47.7 \%$ of which occurred in the developing countries. Lung cancer is 2.7 times less frequent among women.

The estimated fraction of occupational cancer ranges between $1-20 \% .^{2}$ The exact proportion can not be determined because of limitations in our current knowledge about the magnitude, duration and the distribution in the population of the exposures to specific carcinogens. Very few data on exposure to

* Section for Occupational Medicine, Faculty of Medicine, University of Bergen, Norway.

Address for correspondence : Dr. Sunil Kumar Joshi

Lecturer,

Kathmandu Medical College, Dept. of Community Medicine

Email: drsunilkj@hotmail.com 
carcinogens are available in developing countries. A large proportion of known carcinogens occurs in occupational settings. Doll and Peto stated that a total of $2-8 \%$ of cancers is attributable to their occupations. Introductory report of International Labour Office from 1999 stated that around 8\% of cancer deaths are attributed to occupation. ${ }^{3}$ The occupational environment provides an ideal opportunity for introducing cancer prevention by eliminating or decreasing the exposure. Many studies in occupational cancer epidemiology show the decrease in the risk of cancer-followed prevention. ${ }^{4}$

Epidemiological studies have identified a wide range of occupational carcinogens, which have been related to an increase in lung cancer risk. Doll and Peto estimated that 15\% of lung cancer in men and 5\% in women in USA could be attributed to occupational exposures. ${ }^{5}$ Vineis and Simonato in a literature review cited attributable risk estimates for occupation and lung cancer that ranged from $4 \%$ to $40 \%{ }^{6}$ Kvåle et al. suggested that 13 to $27 \%$ of the lung cancer patients could be attributed to occupational exposures.?

The present study was carried out to analyse the association between lung cancer and occupational exposures in Nepal, where lung cancer is the main cause of mortality from cancer in men. ${ }^{8}$ No research on cancer has been performed in Nepal. The whole effort of the health personnel is put in treatment of the cancer patients and in awareness arising programs like consciousness about early signs, disadvantages of smoking and alcohol.

The objective of the study was to describe the relationship between occupational exposures and the development of lung cancer among patients attending a cancer care hospital in Nepal.

\section{METHODS}

A case-control study was designed. The study subjects consisted of all cases of lung cancer and a reference group of all cases of colon cancer that attended Bhaktapur Cancer Hospital from $\mathrm{P}^{\mathrm{t}}$ July to $16^{\text {th }}$ October 2001. All subjects were asked individually to participate in the study and agreed verbally to this. Confidentiality of all information about the subjects was assured.

Resources were not available to construct a population based control group. Instead, the decision to include colon cancer patients as a reference group was made on the basis that very few occupational carcinogens are known to cause colon cancer.

The patients were interviewed in the presence of their close relatives. It was a structured interview, in a questionnaire format. Information about their education, father's occupation, family history of cancer, present and past medical history, diet pattern, smoking habit, history of alcohol intake, present and past heating and cooking system at home, intake of any carcinogenic drug were obtained. A detailed past and present occupational history was recorded for all subjects. Questionnaire about the occupation included information like location of different work places, duration worked in those occupations, types of industries and job duties.

Based on the occupational history, subjects were divided into exposed and non-exposed groups concerning carcinogenic agents. Exposure prone occupations like agriculture, construction of buildings, construction of roads and bridges, manufacturing, and transport were categorised as exposed occupations. Similarly, occupations like administrative services, business, student and housewives were categorised as non-exposed.

A detailed smoking history was obtained for all subjects who had ever smoked regularly for more than six months. This information comprised age at start of smoking, duration of smoking, amount of tobacco smoked and age at any major change in smoking habits. Subjects who have been smoking for at least six months during the study were considered as smokers, whereas subjects who never had smoked for at least six months were considered as non-smokers. Smoking pack year is the cumulative consumption of cigarette through out the whole life. One smoking pack year denotes the smoking of one pack of cigarette per day for one year.

Statistical analysis was done using the statistical program package "Statistical Package for Social Sciences (SPSS)" eleventh version. Odd ratios (OR) and their 95\% confidence intervals $(95 \% \mathrm{CI})$ for lung cancer were estimated for categorical variables using logistic regression models. For continuous variables, $\mathrm{p}$-values with $95 \%$ confidence intervals were calculated using independent samples t-tests. Adjustments for smoking habit, smoking pack year, history of alcohol, education level and age were done by the use of multivariate logistic regression analyses.

\section{RESULTS}

There were 85 cases of lung cancer and 40 cases of colon cancer. Among the cases of lung cancer, $68.2 \%$ cases were males and $31.8 \%$ were females. There were $67.5 \%$ males and $32.5 \%$ females among the colon cancer cases. Mean age for the lung cancer and colon cancer cases differed significantly between the groups, 59 and 42 years, respectively (Table I). A significantly higher number of the lung cancer cases was uneducated compared to the colon cancer cases (Table II). $42.4 \%$ of the lung cancer cases and $20 \%$ of the colon cancer cases had ever consumed alcohol in the past. The number of non-smokers for the lung cancer cases was low (15.3\%) 
compared to the number of non-smokers in the control group $(65 \%)$. Mean smoking pack year for the cases and controls were 19 and 3.1, respectively (Table I)

Variables like sex, diet, father's history of occupation, family history of cancer, history of carcinogenic drugs, heating and cooking habit were not significantly different between the cases and the controls.

Among the cases 23 subjects had worked in non-exposed and 62 in exposed occupations whereas among the controls 27 subjects had worked in non-exposed and 13 in exposed occupations.

Odds ratios and $95 \%$ confidence intervals for lung cancer are shown in table III. Variables that differed in the lung cancer and colon cancer cases, i.e. smoking habit, alcohol habit, education level, age and smoking pack year were adjusted for.

Table I : General information about lung and colon cancer subjects for age and smoking pack years

* Analysed by t-test

Table II : General information about lung and colon cancer subjects for some categorical variables

* Reference category of the respective variables ** Analysed by logistic regression

Table III : Comparison of occupations among cases and referents

* Analysed by multivariate regression analysis
There was a significant excess risk of lung cancer for the exposed workers. The crude OR for the exposed workers was 5.59 (95\% CI: 2.47,12.6). After adjustment for smoking habit alone and for smoking habit, alcohol habit, smoking pack year, education and age altogether the OR was 4.8 (95\% CI: $2.02,11.4)$ and 4.2 (95\% CI: $1.4,12)$, respectively.

\section{DISCUSSION}

We found a high odd ratio for lung cancer among the exposed workers even after adjustment with potential confounders like smoking habit, smoking pack year, age and education level. This was found despite the low number of cases in our study. Our $95 \%$ confidence interval was wide due to the small sample size.

The study subjects consisted of 85 cases of lung cancer and a reference group of 40 cases of colon cancer. The decision to include colon cancer patients as a reference group was made on the basis that occupation in general is likely to play a small role in colon cancer aetiology, with perhaps its major contribution an indirect one via physical activity. ${ }^{9}$

An excess of colon cancer is reported among white-collar occupations with low physical activities, including administrators, professionals, and clerical and sales workers. ${ }^{10-14}$

A potential limitation of this study is information bias. With regard to information bias, two sources must be considered: reliance on type of industries for determining exposure status and use of occupational histories obtained by interviews, which were not further validated.

In the context of this study, self reported information about the type of industries was the only feasible approach for classifying exposure status. The study was hospital based and the reported industries were in diverse geographic locations. Due to the time and logistics constraints, the subjects' tasks could not be validated from the respective industries. Grouping by different exposures was thus not possible. Non-differential misclassification can be anticipated from this approach. Such non-differential misclassification would bias the OR towards no difference. 15

Subjects were divided into exposed and non-exposed groups concerning carcinogenic agents. This was a rather rough categorisation due to the low number of cases, giving a group of very mixed exposure to carcinogens. The categorisation of housewives as non-exposed might be questioned since they might be exposed to volatile organic compounds (VOC) and polycyclic aromatic hydrocarbons (PAH) everyday. ${ }^{16,17}$ There 
is some evidence that indoor air pollution may increase the risk of lung cancer for non-smoking women. ${ }^{17-20}$

No previous studies on occupational cancer have been done in Nepal. Several studies carried out in developed countries showed an association between occupational exposures and lung cancer. Comparison with such studies is of limited value because of potential difference in work environment exposures, between Nepal and developed countries.

In several studies, the lung cancer risk in subjects working in agriculture, construction, driving, manufacture, and the combination of different occupations was found to be higher compared to administrative staff workers. This was found also after adjustments for smoking. This is in concordance with the findings of the present study.

Some studies have shown increased risk of lung cancer among agriculture workers. ${ }^{21-26}$ An elevated risk of lung cancer has been observed among sugarcane farmers. ${ }^{21,25}$ A study done in Gaza showed a highly significant positive correlation between the use of pesticides and lung cancer incidence. ${ }^{22}$ Barthel $\mathrm{E}$ observed a high incidence of lung cancer in agriculture workers with chronic occupational exposure to pesticides. ${ }^{23}$ Exposure to agents like herbicides (MCPA), insecticides (DDT, $\mathrm{HCH}$ and Toxaphen), organic phosphorus compounds (Parathion), organic nitro derivatives and fungicides have been related to these findings. ${ }^{23,24}$

Furthermore, high risks for lung cancer have been observed for the agriculture workers $(\mathrm{OR}=1.8,95 \% \mathrm{CI}=1.1,3.1)$, drivers $(\mathrm{OR}=1.9,95 \% \mathrm{CI}=1.1,4.0)$ and construction workers $(\mathrm{OR}=2.5,95 \% \mathrm{CI}=1.0,5.9)$ in a hospital based case-control study done by Pezzotto and Poletto in Argentina. ${ }^{27}$

For the workers in the construction industry the mortality odds ratio (135 95\% CI: 129, 140) for lung cancer is high. ${ }^{28}$ A cohort study done by Rafnsson $\mathrm{V}$ et al. showed an increased risk of lung cancer among the masons, which could be due to exposure to hexavalent chromium in the cement. ${ }^{29}$

In a hospital based case-control study Matos E et al. observed elevated odd ratios for lung cancer among employees in the alcoholic beverages industry (4.5, 95\% CI: 1.02-20.2), sawmills and wood mills (4.6, 95\% CI: 1.1-18.4) and chemicals / plastic manufacturers (1. 8, 95\% CI: 1.04-3.2). ${ }^{30}$

Hospital based case-control studies using only cancer controls like in the present study were not found in the literature. Previous lung cancer studies are cohort studies, hospital based case-control studies with non-cancer hospital controls or/and population controls, and population based case-control studies.
Previous epidemiological studies done in other developing countries strongly indicates that there are many occupations and industries in Nepal with possible exposure to carcinogens. The government bodies do not have full information about the types of occupational carcinogens present in the industries in Nepal. It is very difficult to achieve information about details concerning carcinogens in the industry in Nepal, but there seems to be a large number of workers who are exposed to different carcinogens in a large number of industries.

This study is one of the first studies on occupational cancer in Nepal. The study demonstrates the need for further research on occupational cancer in Nepal with larger populations, refining different occupational groups.

\section{ACKNOWLEDGEMENT}

This study was supported by the Norwegian Agency for Development Cooperation (NORAD).

\section{REFERENCES}

1. Parkin DM, Pisani P, Lopez AD, Masuyer E: Atleastone in seven cases of cancer is caused bysmoking. Global estimates for 1985. IntJ Cancer, 1994; 59: 494-504.

2. Vainio $H$, Matos $E$, Boffeta $P$, Kogevinas $M$, Wilbourn J . Occupational Cancer in Developing and newly industrialized countries. Annals Academy of Medicine, 1993; 22:170-181.

3. Yakala J . Introductory reportof the International Labor Office, ILO (23.09.1999).

4. Simonato $L, L$ 'Abbe KA, etal. A collaborative study of cancer incidence and mortalityamong vinyl chlorideworkers. Scand] Work Environ Health, 1991; 17:159-169.

5. Doll R, Petto R. The causes of cancer: quantitative estimates of avoidable risks of cancer in the United States today, J Natl Cancer Inst, 1981; 66:1196-1305.

6. Vineis $P$, Simonato L. Proportion of lung and bladder cancers in males resulting fromoccupation: a systematic approach. Arch Environ Health, 1991; 46:6-15.

7. Kvåle G, BjelkeE, Heuch I. Occupational exposure and lung cancer risk. IntJ Cancer, 1986; 37: 185-193.

8. Globocan 2000 Database. Intemational Agency forResearch on Cancer, World Health Organization.

9. ChowWH, MalkerHS, Hsing AW, McLaughlin J K, WeinerJ A, Stone BJ , Ericsson J L,

10. BlotWJ .Occupational risks forcoloncancerinSweden.J Occup Med., 1994J un; 36(6): 647-51.

11. Chow WH, Dosemeci M, Zheng, W, Vetter R, McLaughlinJ K, GaoYT, BlotWJ .Physical activityandoccupational risk of colon cancerin Shanghai, China. IntJ Epidemiol, 1993 Feb; 22(1): 23-9. 
12. Lynge $E$, Thygesen $L$. Use of surveillance systems for occupational cancer: data from the Danish National system. IntJ Epidemiol, 1988 Sep; 17(3): 493-500

13. Garabrant, DH, Peters J M, Mack TM, Bernstein L. J ob activity and colon cancer risk. AmJ Epidemiol, 1984 J un; 119(6): 1005-14.

14. Hsing AW, McLaughlinJ K, ChowWH, Schuman LM, Co-Chien HT, Gridley G, Bjelke E. WacholderS, BlotWJ . Risk factors for colorectal cancerina prospective studyamong U.S. whitemen. IntJ Cancer, 1998 Aug 12; 77(4): 549-53.

15. Slattery ML, Abd-Elghany N, Kerber R, Schumacher MC. Physical activity and colon cancer: a comparison of various indicators of physical activity to evaluate the association. Epidemiology, 1990 Nov; 1(6): 481-5.

16. Lerchen $M L$, Wiggins $C L$, Samet J M. Lung cancer and occupation in NewMexico.J Natl Cancer Inst, Vol.79, October 1987; 639-645.

17. Mishra SB, Kayastha RP. Air quality. A Compendium on Environmentstatistics 1998, Nepal, 1998; 174-183.

18. PanditGG, SrivastavaPK, RaoAM. Monitoring ofindoorvolatile organic compounds and polycyclic aromatic hydrocarbons arising fromkerosene cooking fuel. Sci Total Environ, 2001 Nov 12; 279(1-3): 159-65.

19. Bruce N, Perez-Padilla R, Albalak R. Indoor air pollution in developing countries: a majorenvironmental and public health challenge. Bull World Health Organ, 2000; 78(9): 1078-92.

20. Liu Q, Sasco AJ , Riboli E, Hu MX. Indoorair pollutionand lung cancer in Guangzhou, People's Republic of China. Am J Epidemiol, 1993J an 15; 137(2): 145-54.

21. Chen BH, Hong CJ , Pandey MR, Smith KR. Indoorair pollution in developing countries. World Health Stat Q, 1990; 43(3): 127-38.
22. Rothschild H, Mulvey J . An increased risk for lung cancer mortality associated with sugarcane farming. J Natl Cancer Inst, 1982 May; 68(5): 755-60.

23. Safi, J M. Association between chronic exposure to pesticides and recorded cases of human malignancy in Gaza Govemorates (1990-1999). Sci Total Environ, 2002 Feb 4; 284(1-3): 75-84.

24. BarthelE. High incidence of lung cancer in persons with chronic professional exposure to pesticides in agriculture. Z Erkr Atmungsorgane, 1976 Sep; 146(3): 266-74.

25. AxelsonO. Pesticides and cancerrisks in agriculture. MedOncol Tumor Pharmacother, 1987; 4(3-4): 207-17.

26. Amre DK, Infante RC, Dufresne A, Durgawale PM, EmstP. Case-control study of lung cancer among sugar cane farmers in India. Occup Environ Med, 1999 Aug; 56 (8): 548-552.

27. Levin LI, Zheng W, BlotWJ , GaoYT, FraumeniJ F. Occupation and lung cancer in Shanghai: a case-control study. BrJ Ind Med., 1988J ul; 45(7): 450-8.

28. PezzottoSM, Poletto L. Occupationand histopathology of lung cancer: A case-control study in Osario, Argentina. AmJ Ind Med, 1999; 36: 437-443.

29. Dong W, Vaughan P, Sullivan K, FletcherT. Mortality study of construction workers in the UK. IntJ Epidemiol, 1995; 24: 750-757.

30. Rafnsson V, Gunnarsdottir H, Kiilunen M. Risk of lung cancer among masons in Iceland. Occup Environ Med, 1997; 54:184188.

31. Matos El, Vilensky M, Boffetta PB. Environmental and occupational cancer in Argentina: a case-control lung cancer study. Cad Saude Publica., 1998; 14Suppl 3: 77-86. 